DOI: 10.20472/IAC.2020.054.004

\author{
NADIM ALFOUHAILI \\ University Paris 1 Panthéon-Sorbonne, Lebanon
}

\title{
THE TRADE-OFF BETWEEN BANKING RISK AND PROFITABILITY UNDER BASEL III CAPITAL REGULATION
}

\begin{abstract}
:
This research examined the trade-off between risk and profitability under Basel III capital regulation (BCR) using a sample of 30 commercial banks in Lebanon. Because our approach in the study is qualitative, we used semi-structured interviews with chief risk officer (CRO) for our sample. In order to examine the impact of Basel III capital regulation (BCR) on risk and profitability, we asked our CFO's to rate risk and profitability based on 5 scale metrics before and after the application Of Basel III in Lebanon. To analyze the data, we used ATLAS. ti version 8.3 software. The results showed that after the application of Basel III accord in Lebanon risk and profitability decreased in banks. We also noticed this effect is much greater in small and high-risk banks. This result aligns with Klomp and de Haan (2012) findings' that the Basel III accord has more effect on small and high-risk banks.
\end{abstract}

\section{Keywords:}

Basel III capital regulation (BCR); Banking risk; Banking Profitability; ATLAS. ti version 8.3 software

JEL Classification: G21, G32 